\title{
Randomized clinical trial comparing manual suture and different models of mechanical suture in the mimicking of bariatric surgery in swine
}

This article was published in the following Dove Press journal:

Open Access Surgery

5 February 2014

Number of times this article has been viewed

\author{
Marcos AP Fernandes' \\ Bruno MT Pereira ${ }^{2}$ \\ Sandra M Guimarães' \\ Aline Paganelli ${ }^{3}$ \\ Carlos Manoel CT Pereira' \\ Claudio Sergio Batista ${ }^{4}$ \\ Institute of Obesity and Advanced \\ Video Laparoscopic Surgery of \\ Petropolis, Rio de Janeiro, Brazil; \\ ${ }^{2}$ Division of Trauma, University \\ of Campinas, São Paulo, Brazil; \\ ${ }^{3}$ Laboratório de Patologia Micron Cell \\ Diagnóstico, Rio de Janeiro, Brazil; \\ ${ }^{4}$ Department of Gynecology and \\ Obstetrics, Faculty of Medicine of \\ Petropolis, Rio de Janeiro, Brazil
}

Correspondence: Claudio Sergio Batista Rua do Imperador 288/908,

Centro, Petropolis, Rio de Janeiro,

Brazil CEP 25620-000

Tel +55 2422455121

Email csergiobatista@gmail.com
Context and objective: Variations in the ability of surgeons served as motivation for the development of devices that, overcoming individual differences, allow the techniques to be properly performed, and of which the end result was the best possible. Every technique must be reproduced reliably by the majority of surgeons for their results to be adopted and recognized as effective. The aim of this study was to compare the results, from the point of view of anatomic pathology, of manual sutures versus mechanical sutures using different models of linear mechanical staplers, in the procedure of gastroenteroanastomosis and enteroanastomosis in swine.

Methods: Thirty-six healthy, adult, male Sus scrofa domesticus pigs, weighing between 20.7 and $25.5 \mathrm{~kg}$, were used. The swine were randomly divided into four groups of nine pigs, according to the type of suture employed: group A, manual suture with Polysorb ${ }^{\circledR}$ 3-0 wire; group B, 80-shear linear stapler (Covidien ${ }^{\circledR}$ Gia 8038-S); group C, 75-shear linear stapler (Ethicon ${ }^{\circledR}$ Tlc 75); and group D, 75-shear linear stapler (Resource ${ }^{\circledR}$ Yq 75-3). A temporal study was established on the seventh postoperative day for histopathological analysis, and the degree of inflammation, fibrosis, and newly formed vessels, as well as the presence or absence of granulation tissue, foreign body granuloma, and necrosis were all evaluated qualitatively and semiquantitatively. The results were analyzed statistically.

Results: Observations during the histopathological analysis included the formation of foreign body granuloma in the gastroenteroanastomosis and enteroanastomosis in $88.9 \%$ of the swine that underwent manual suture and in none of the swine that underwent stapling. There was also a significant statistical difference among swine from Group A, and those from groups $\mathrm{B}, \mathrm{C}$ and $\mathrm{D}$ regarding the degree of inflammation, being more intense in those swine that underwent manual suture.

Conclusion: This study shows that both types of suture promoted proper healing of gastroenteroanastomosis and enteroanastomosis, although there was a higher degree of inflammation and an increased occurrence of foreign body granuloma in swine subjected to manual suture, although there have been similarities in safety, efficiency, and effectiveness between the models of linear mechanical staplers tested during the performance of these anastomoses on swine.

Keywords: linear mechanical stapler, stapler, manual suture, surgery, gastroenteroanastomosis, enteroanastomosis, swine, randomized clinical trial

\section{Introduction}

The goal of any surgeon in performing any intervention is that it be safe and efficient. The procedure should be as fast as possible, with the least tissue trauma and quick restoring function, and, consequently, minimization of the possibility of postoperative complications. ${ }^{1,2}$ It was only in the late 19th century, however, that gastrointestinal sutures became reliable, due to an acquired knowledge of the principles of

submit your manuscript | www.dovepress.com 
tissue healing. ${ }^{3}$ The factors involved in tissue repair are related not only to technique but also to the individual patient and the area to be operated. The presence of ischemia, edema, infection, and malnutrition are some of the elements that hinder the healing process. ${ }^{3}$

Humer Hultz, a Hungarian surgeon, was the first, in 1908 , to use a stapler for digestive anastomosis. Despite great success at the time, use of the device was abandoned because of its drawbacks: excessive weight and complexity of use. ${ }^{4,5}$ Based on studies by Ravitch et al in 1966, ${ }^{7}$ US companies entered the market, offering lighter staplers of more modern design, as this procedure (mechanical sutures with Russian staplers models), offered more security than others previously had. Shortly thereafter, disposable cartridge systems with various applications were developed. Thus, the devices themselves could be used more than once by changing only the refill unit, which could contain staples of different sizes. ${ }^{6-8}$ The benefits of the use of staplers were much appreciated, which led to further research and the development of multipurpose devices. Mechanical sutures are more quickly created than manual sutures. This reduces operating time, which is very important for clinically severe patients undergoing surgery. ${ }^{3,7,9}$ Another advantage of using mechanical sutures is in the case of anastomoses, or in unfavorable anatomical locations for manual sutures, such as in cases of low rectal and esophageal anastomoses, or in obese patients. The cost of using a stapler is high, and its indication should be based on the real advantages of its use..$^{2,3,10}$

It is of great importance to the final outcome of sutures, be they done manually or mechanically, to take care in all processes, such as with hemostasis, dissection and suitable preparation of the edges to be sutured, blood supply, and lack of tension in the suture line. ${ }^{10,11}$ Accordingly, the literature has proven that there are no substantial differences in the end results of manual sutures and those made by staplers. ${ }^{11}$ Likewise, the literature shows no significant differences in the onset of complications and shows that the use of staplers is effective and safe. ${ }^{1-3,6-8,11}$

\section{Objective}

To compare the safety and efficacy, from the point of view of anatomic pathology, between different models of staplers and manual sutures in the performance of anastomosis in swine.

\section{Methods}

Thirty-six healthy, adult, Sus scrofa domesticus male pigs were used in this study, with body weight ranging from 20.7 to $25.5 \mathrm{~kg}$. The animals were placed in individual cages with ambient light, adequate sanitary conditions, and clean water available. The distribution of the animals into four groups, named, respectively, A, B, C, and D, was random, differing only in the technique and model of mechanical stapler employed, as follows:

1. Group A: manual suture with Polysorb ${ }^{\circledR}$ 3-0 wire (Covidien, Dublin, Ireland) (90\% polylactic acid and $10 \%$ polyglycolic acid).

2. Group B: mechanical suture with 80 -shear linear stapler (Gia 8038-S; Covidien, Dublin, Ireland).

3. Group $\mathrm{C}$ : mechanical suture with 75-shear linear stapler (Tlc 75; Ethicon ${ }^{\circledR}$; Johnson \& Johnson, New Brunswick, NJ, USA).

4. Group D: mechanical suture with 75-shear linear stapler (Yq 75-3; Resource ${ }^{\circledR}$ Yq 75-3; Changzhou Resource Medical Devices Co., Ltd., Changzhou, People's Republic of China).

During the preoperative period, the animals received a liquid diet for 12 hours and then were fasted for 12 hours, totaling 24 hours of preparation.

The antimicrobial preparation in all animals was carried out with hydroxy-2 methyl-2, nitro-5, imidazole (metronidazole) in vials of $100 \mathrm{~mL}$ of $0.5 \%$ solution (500 mg), administered intravenously at a dose of $22.5 \mathrm{mg} / \mathrm{kg}$ during the anesthetic induction, and sodium cephalothin at a dose of $100 \mathrm{mg} / \mathrm{kg}$ preoperatively ( 6 hours before surgery), during anesthetic induction, and postoperatively (6 hours after surgery).

Prior to receiving anesthetic, the animals received midazolam (Dormonid ${ }^{\circledR}$; Hoffman-La Roche, Basel, Switzerland) intramuscularly at a dose of $2.5 \mathrm{mg} / \mathrm{kg}$, and ketamine hydrochloride (Ketalar ${ }^{\circledR}$; Pfizer, NY, USA) intramuscularly at a dose of $8.0 \mathrm{mg} / \mathrm{kg}$. The animals were anesthetized after 15 minutes of pre-anesthetic medication with sodium thiopental at $2.5 \%$ (Thionembutal $^{\circledR}$; Abbott Laboratories, IL, USA) intravenously at a dose of $10-12 \mathrm{mg} / \mathrm{kg}$.

The animals underwent general anesthesia with fentanyl citrate (Fentany ${ }^{\circledR}$; Janseen-Cilag, Beerse, Belgium) intravenously at a dose of $0.012 \mu \mathrm{g} / \mathrm{kg}$ and muscle relaxation with alcuronium chloride (Alloferine ${ }^{\circledR}$; Valeant Pharmaceuticals, Laval, QC, Canada) intravenously at a dose of $1.1 \mathrm{mg} / \mathrm{kg}$, with orotracheal intubation and assisted respiration using a model 660 Takaoka apparatus.

During surgery, physiological glucose solution was administered ( $5 \%$ glucose and $0.9 \%$ sodium chloride) by continuous intravenous infusion, $2 \mathrm{~g}$ of vitamin $\mathrm{C}, 2 \mathrm{~mL}$ of $\mathrm{B}$ complex, and further addition of anesthetic as required. For resuscitation, the anesthetic nalorphine hydrochloride (Nalorfine $^{\circledR}$; Janssen-Cilag) was administered intravenously at a total dose of $0.4 \mathrm{mg}$ and neostigmine (Prostigmine ${ }^{\circledR}$; Valeant Pharmaceuticals) intravenously at a dose of $0.1 \mathrm{mg} / \mathrm{kg}$. 


\section{Surgical technique}

The anesthetized animals were placed in the supine position on the operating table, in a supporting tray, and immobilized by securing all the limbs. Trichotomy was not performed on these animals. Antiseptic procedure was performed with Povidine ${ }^{\circledR}$ solution; SC Johnson, Racine, WI, USA, carefully observing all the precepts of the aseptic technique.

The following techniques were employed in all four groups:

1. The swine were submitted to a supraumbilical median laparotomy with an incision of $15 \mathrm{~cm}$ (see Figure 1). The abdominal wall was separated with a Finochietto infantile retractor (Quinelatto ${ }^{\circledR}$; Avenida Pennwalt, Sao Paulo, Brazil). Random grouping of the animals into the following: group A, involving septation of the stomach and closing of the proximal and distal stump with a manual suture instrument, with simple sutures with Polysorb ${ }^{\circledR} 3-0$ wire (90\% polylactic acid and $10 \%$ polyglycolic acid), with $0.5 \mathrm{~cm}$ between the sutures, as well as reconstruction by gastroenterostomy and Braun enteroentero; group B, involving septation of the stomach with an 80-shear linear stapler (Covidien ${ }^{\circledR}$ Gia 8038-S) and reconstruction by gastroenterostomy and Braun enteroentero; group C,

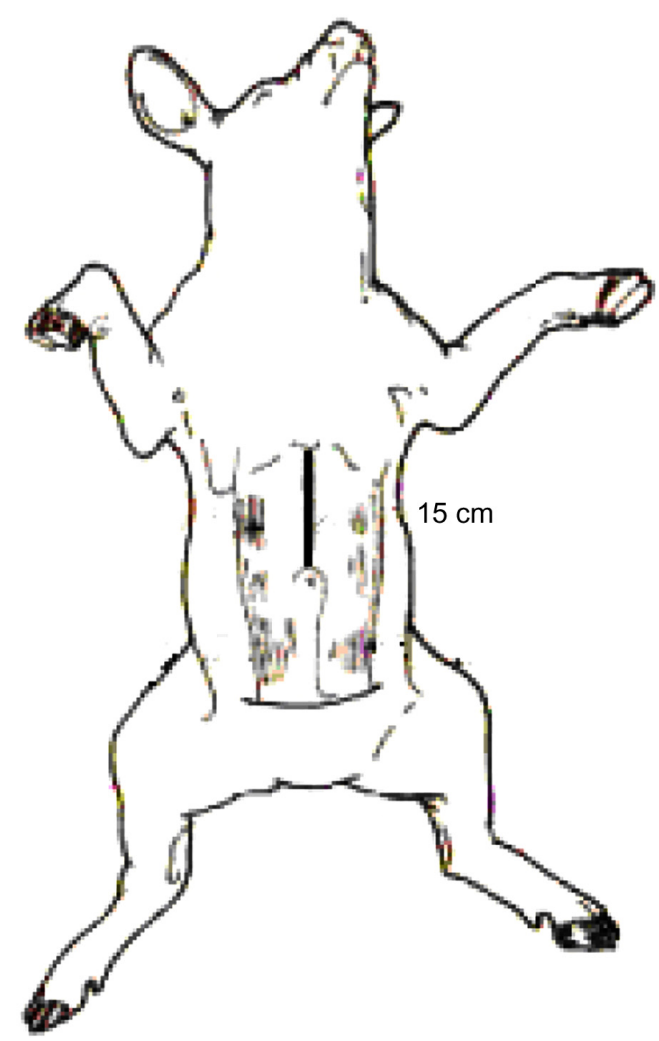

Figure I Positioning of the pigs.

Note: Measurement refers to incision length.

involving septation of the stomach with a 75-shear linear stapler (Ethicon ${ }^{\circledR}$ Tlc 75$)$ and reconstruction by gastroenterostomy and Braun enteroentero; and group D, involving septation of the stomach with a 75 -shear linear stapler (Resource ${ }^{\circledR} \mathrm{Yq}$ 75-3) and reconstruction by gastroenterostomy and Braun enteroentero.

2. Visualization and inventory of the abdominal cavity.

3. Fixation of the urinary bladder to the anterior abdominal wall by a transfixed point and execution of a puncture in the organ with aspiration of its contents.

4. Liberation of the stomach with an incision along the lesser curvature of the hepatogastric ligament, about $5 \mathrm{~cm}$ below the esophagogastric junction, and dissection with scissors of the posterior mesogastrium in caudal direction, until $1 \mathrm{~cm}$ below the peritoneal reflection of the stomach. Identification of the left gastric artery and its terminal branches. Clipping and sectioning of these terminal branches.

5. Liberation of the stomach with an incision along the greater curvature of the gastrocolic ligament, about $10 \mathrm{~cm}$ below the esophagogastric junction.

6. Identification of the angle of Treitz, measuring $20 \mathrm{~cm}$ from this point forward to the jejunum.

7. Performance of gastroenteroanastomosis (see Figure 2).

8. Performance of Braun enteroanastomosis $5 \mathrm{~cm}$ from the angle of Treitz (see Figure 3).

9. Aspiration of the intracavity liquids, removing the Finochietto infantile retractor (Quinelatto ${ }^{\circledR}$ ) and closure of the aponeurosis with 2-0 cotton wire, and skin with 3-0 nylon wire, both of them with separate points.

The following techniques were employed distinctly in the different groups:

1. Group A: delimitation of the gastric segment to be partitioned. Placing atraumatic intestinal tweezers for gastric septation, keeping a minimum distance of $4 \mathrm{~cm}$ between atraumatic intestinal tweezers. Sectioning of

A
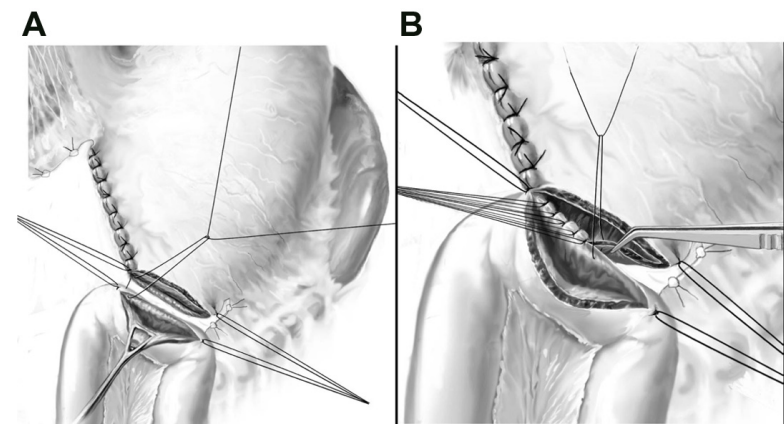

Figure 2 Performance of gastroenteroanastomosis.

Notes: (A) Stomach and jejuno approximation and their incision for anastomose confection. (B) posterior wall closure for anastomose installation. 


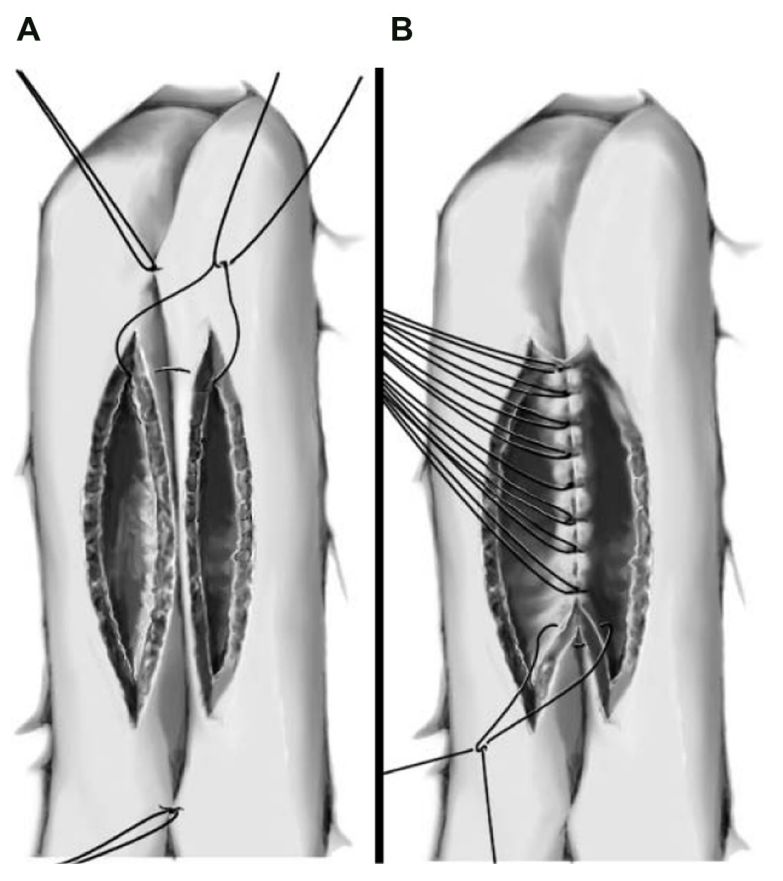

Figure 3 Performance of entero-enteroanastomosis.

Note: (A) Jejuno-jejunal approximation and their incision for anastomose confection. (B) Posterior wall closure for anastomose installation.

the gastric antrum with scissors, maintaining a similar distance between the extremities. Closure of the distal gastric stump using a needle holder for the application of sutures by Polysorb ${ }^{\circledR}$ 3-0 wire with separate sutures, paying attention to all layers of the wall.

2. Group B: introduction of the Covidien ${ }^{\circledR} 80$-shear linear stapling device with clamping and firing of the device, which simultaneously severs and closes both intestinal segments.

3. Group C: introduction of the Ethicon ${ }^{\circledR} 75$-shear linear stapling device, with clamping and firing of the device, which simultaneously severs and closes both intestinal segments.

4. Group D: introduction of the Resource ${ }^{\circledR} 75$-shear linear stapling device, with clamping and firing of the device, which simultaneously severs and closes both intestinal segments.

\section{Postoperative procedures}

The animals were kept in individual cages, with parenteral hydration in the immediate postoperative period and the introduction of oral feeding 24 hours after surgery. They then received a liquid diet on the first postoperative day, and, subsequently, swine feed.

All animals were clinically evaluated at least twice a day in the postoperative period until the date on which they were sacrificed. The behavior of the animals was observed, especially their physical activity, feeding, locomotion, and defecation.

On the seventh postoperative day, the animals were anesthetized with sodium thiopental (thionembutal; Abbott
Laboratories) and submitted to a median infra umbilical laparotomy for investigation of the abdominal cavity and removal of the stomach and small intestine (collectively), comprising the anastomotic regions previously performed. The animals were then sacrificed, using an increased dose of anesthetic.

On checking the abdominal cavity, the presence of adhesions in the region of the incision was observed, with no signs of peritonitis, adhesions between abdominal organs, abscesses, fistulas, nor anastomotic dehiscence.

The stenosis index was checked and the parameter for this examination was the measurement, in centimeters, of the intestinal diameter at the level of the anastomosis, compared with that of the neighboring segments. This was calculated using the following formula:

$$
\text { Stenosis index }=100 \times(1-[2 \mathrm{~A} /\{\mathrm{B}+\mathrm{C}\}]),
$$

where $\mathrm{A}=$ diameter at the suture level and $\mathrm{B}$ and $\mathrm{C}=$ intestinal diameters, $2 \mathrm{~cm}$ above and $2 \mathrm{~cm}$ below the anastomosis, respectively. The parts removed were examined at the suture line, with the purpose of highlighting, macroscopically, the integrity or presence of epiploic block, dehiscence, fistula path, and abscesses.

$\mathrm{CO}_{2}$ gas was introduced with a constant pressure of $15 \mathrm{mmHg}$ of mercury in the lumen of the removed part, which was submerged in saline to detect leaks. After this insufflation test, the parts were opened longitudinally and examined according to the criteria established for macroscopic observation. Thus, the appearance of the mucosa was classified as "normal" when no changes were noticed and as "altered" when hyperemia, necrosis, hemorrhage, ulcers, abscesses, or fistulas at the suture line occurred.

For microscopic examination of the anastomosis, a $1 \mathrm{~cm}$-wide fragment was removed, with the suture line being in the middle of the specimen. For the histological examination, the intestinal fragments obtained from the areas of anastomoses were fixed in Bouin solution $(250 \mathrm{~mL}$ of $40 \%$ formaldehyde solution, $750 \mathrm{~mL}$ of picric acid, and $5 \mathrm{~mL}$ of acetic acid) and, after the removal of the sutures from groups B, C, and D, 5 micron-thick slices were taken, which were then stained with hematoxylin and eosin solution, with the aim of evaluating the evolution of healing at the suture line and wall thickness. The criteria adopted for the quantification of histopathological findings were as follows:

1. In the exudative inflammation response, an indicator of the acute phase, changes such as edema, vascular congestion, and neutrophil influx were observed and quantified as (-) for absent or (+) for present. 
2. In the chronic inflammation response, an indicator of the reparative phase, the changes studied were fibrosis and mononuclear infiltration, which were quantified as (-) for absent or $(+)$ for present.

3. The presence of ulcerations and granulomatous reaction was also observed and quantified as $(-)$ for absent or $(+)$ for present.

\section{Statistical analysis}

For analysis of the results, the following tests were applied:

1. Fisher's exact test, with the aim of studying the presence or absence of the studied characteristics, comparing group A with groups B, C, and D; and

2. the Mann-Whitney test, to compare group A with groups B, C, and D for the stenosis index.

Fisher exact test was used in order to study the presence or absence of traits between group A and group B, C and D. The histological analysis of the data taken by the Fisher exact test. Statistical tests were performed by GraphPad InStat 3.1 and StatMet. An $\alpha$-value of 0.05 or $5 \%$ was fixed as the rejection level of the null hypothesis.

\section{Results}

The results obtained are summarized in the tables below, following the macroscopic and microscopic findings after sacrificing the pigs. In the evaluation of the peritoneal cavity, no peritonitis, adhesion in the regions, nor abscesses were observed.

Although no peritonitis was observed (Table 1) the presence of adhesion between the anastomotic region with omentum and the small bowel was observed in $50 \%$ of the animals, with no statistical differences among the four groups $(P=0.3523)$. Only one macroscopic anastomotic fistula was found in group A, animal number 5, and none in groups $\mathrm{B}, \mathrm{C}$, or $\mathrm{D}$, but without statistical significance $(P=0.4500)$.

The gas insufflation test did not identify the presence of gas leakage by a fistula path (Tables 2 and 3), neither in the suture line as shown (Table 4), even in animals number 5

Table I Presence of abdominal peritonitis

\begin{tabular}{lllll}
\hline Group & Present & Absent & Total & \% present \\
\hline A & 0 & 9 & 9 & $0.00 \%$ \\
B & 0 & 9 & 9 & $0.00 \%$ \\
C & 0 & 9 & 9 & $0.00 \%$ \\
D & 0 & 9 & 9 & $0.00 \%$ \\
Total & 0 & 36 & 36 & $0.00 \%$ \\
\hline
\end{tabular}

Note: Columns refer to numbers of pigs.
Table 2 Macroscopic presence of a fistula in the anastomotic region

\begin{tabular}{lllll}
\hline Group & Present & Absent & Total & \% present \\
\hline A & I & 8 & 9 & $11.11 \%$ \\
B & 0 & 9 & 9 & $0.00 \%$ \\
C & 0 & 9 & 9 & $0.00 \%$ \\
D & 0 & 9 & 9 & $0.00 \%$ \\
Total & 1 & 35 & 36 & $2.77 \%$ \\
\hline
\end{tabular}

Notes: $P=0.4500$. Columns refer to numbers of pigs.

and 7 from group A and number 6 from group C, which presented anastomotic fistulas. In animal number 5 from group A, the fistula path was blocked by adhesions between the anastomosis, the omentum, and small bowel, while in animal number 7 from group A and in number 6 from group $\mathrm{C}$, the fistulas were only noticeable on microscopic examination.

The presence of macroscopic mucosal necrosis was found in one animal, number 3 from group B (Table 5), while, in the remaining animals, the presence of macroscopic necrosis at the suture line was not observed. The stenosis index was apparently similar in both anastomosis groups (Table 6). The presence of edema, vascular congestion, neutrophil influx, and ulcerations were similar in all groups (Table 7). The healing process in the chronic phase was also similar among all the groups (Tables 8 and 9), with no significant statistical difference $(P=0.7105)$.

Microscopic anastomotic fistulas were found in three animals, that is, two from group A (numbers 5 and 7 ) and one from group C (number 6), but with no significant statistical difference (Table 9).

The presence of necrosis was found in four animals, one from each group (animal number 2 in group A, number 7 in group $\mathrm{B}$, number 1 in group $\mathrm{C}$, and number 4 in group $\mathrm{D}$ ), with no significant statistical difference (Table 10).

In animal number 8 from group $\mathrm{C}$, the presence of necrosis was noted during the microscopic study (Table 10). Interstitial hemorrhage occurred in both animal number 3 from group A and animal 8 from group C.

Table 3 Microscopic presence of fistulas along the line of the sutures

\begin{tabular}{lllll}
\hline Group & Present & Absent & Total & \% present \\
\hline A & 2 & 7 & 9 & $22.22 \%$ \\
B & 0 & 9 & 9 & $0.00 \%$ \\
C & 1 & 8 & 9 & $11.11 \%$ \\
D & 0 & 9 & 9 & $0.00 \%$ \\
Total & 3 & 33 & 36 & $8.33 \%$ \\
\hline
\end{tabular}

Notes: $P=0.4210$. Columns refer to numbers of pigs. 
Table 4 Presence of gas escaping through the suture

\begin{tabular}{lllll}
\hline Group & Present & Absent & Total & $\%$ present \\
\hline A & 0 & 9 & 9 & $0.00 \%$ \\
B & 0 & 9 & 9 & $0.00 \%$ \\
C & 0 & 9 & 9 & $0.00 \%$ \\
D & 0 & 9 & 9 & $0.00 \%$ \\
Total & 0 & 36 & 36 & $0.00 \%$ \\
\hline
\end{tabular}

Note: Columns refer to numbers of pigs.

Table 5 Presence of necrosis observed macroscopically in the anastomotic region

\begin{tabular}{lllll}
\hline Group & Present & Absent & Total & $\%$ present \\
\hline A & 0 & 9 & 9 & $0.00 \%$ \\
B & 1 & 8 & 9 & $11.11 \%$ \\
C & 0 & 9 & 9 & $0.00 \%$ \\
D & 0 & 9 & 9 & $0.00 \%$ \\
Total & 1 & 35 & 36 & $2.77 \%$ \\
\hline
\end{tabular}

Notes: $P=0.5500$. Columns refer to numbers of pigs.

Table 6 Pigs undergoing to laparotomy according to the stenosis index

\begin{tabular}{llll}
\hline Group A & Group B & Group C & Group D \\
\hline-4 & 15 & 0 & 6 \\
1 & 12 & 6 & 12 \\
3 & 0 & 16 & 15 \\
20 & 9 & 6 & 5 \\
13 & 5 & 6 & 36 \\
19 & 16 & 0 & 9 \\
-1 & 0 & 7 & 3 \\
11 & 6 & 11 & 1 \\
7 & 6 & 0 & 0 \\
7.67 & 7.45 & 7.38 & 7.31 \\
U calc $=47$ & U crit $=23$ & & \\
\hline
\end{tabular}

Notes: $U$ crit is the Critical Value of $U$, as determined by the Mann-Whitney Test. $Y$ calc is the U-value calculator, as determined by the Mann-Whitney Test.

Table 7 Presence of edema found in the acute phase of the healing process

\begin{tabular}{lllll}
\hline Group & Present & Absent & Total & \% present \\
\hline A & 4 & 5 & 9 & $44.44 \%$ \\
B & 3 & 6 & 9 & $33.33 \%$ \\
C & 4 & 5 & 9 & $44.44 \%$ \\
D & 5 & 4 & 9 & $55.55 \%$ \\
Total & 16 & 20 & 36 & $44.44 \%$ \\
\hline
\end{tabular}

Notes: $P=0.3424$. Columns refer to numbers of pigs.

Table 8 Presence of fibrosis found in the chronic phase of the healing process

\begin{tabular}{lllll}
\hline Group & Present & Absent & Total & $\%$ present \\
\hline A & 9 & 0 & 9 & $100 \%$ \\
B & 9 & 0 & 9 & $100 \%$ \\
C & 9 & 0 & 9 & $100 \%$ \\
D & 9 & 0 & 9 & $100 \%$ \\
Total & 36 & 0 & 36 & $100 \%$ \\
\hline
\end{tabular}

Note: Columns refer to numbers of pigs.
Table 9 Presence of granulomatous reaction found in the chronic phase of the healing process

\begin{tabular}{lllll}
\hline Group & Present & Absent & Total & \% present \\
\hline A & 8 & 1 & 9 & $88.89 \%$ \\
B & 8 & 1 & 9 & $88.89 \%$ \\
C & 7 & 2 & 9 & $77.77 \%$ \\
D & 7 & 2 & 9 & $77.77 \%$ \\
Total & 30 & 6 & 36 & $83.33 \%$ \\
\hline
\end{tabular}

Notes: $P=0.7105$. Columns refer to numbers of pigs.

\section{Discussion}

Technology is an inseparable part of modern surgery. The surgeon should study and practice to be able to decide when to use certain techniques or particular instruments. The medical equipment industry apply seductive pressure to physicians to use their devices. This subtle pressure must be managed wisely by doctors, at risk of introducing a bias in a relationship that should be free of any commercial interests. Companies invest in research and relentlessly seek improvements and innovations in the products they sell; on the other hand, both public and private health systems are eager for cost reduction. , $^{8,13}$

There is no doubt that stapling equipment increases the costs of the suturing procedure. This is perhaps the biggest barrier to its full utilization; however, it should be kept in mind that the costs of treating complications could be much higher than the price of the unused equipment. It falls on the surgeon to make an analysis of the costs and benefits in indicating the use of stapling devices. There are situations in which staplers are essential and others in which they are dispensable. The surgeon should be able to exercise this choice independently, based solely on the best outcome for the patient. ${ }^{12,13}$

Mechanical anastomosis, in surgery of the digestive tract, is an established surgical method and is mandatory whenever possible. Technological advances have enabled the development of linear staple devices that facilitate the performance of anastomosis and decrease intraoperative surgical duration. The same procedure with manual sutures is, however, still feasible and presents good results. ${ }^{14-16}$

Table 10 Presence of necrosis along the line of the sutures

\begin{tabular}{lllll}
\hline Group & Present & Absent & Total & $\%$ present \\
\hline A & I & 8 & 9 & $11.11 \%$ \\
B & 1 & 8 & 9 & $11.11 \%$ \\
C & 1 & 8 & 9 & $11.11 \%$ \\
D & 1 & 8 & 9 & $11.11 \%$ \\
Total & 4 & 32 & 36 & $11.11 \%$ \\
\hline
\end{tabular}

Notes: $P=0.7105$. Columns refer to numbers of pigs. 
The choice to use swine in this study was due to the anatomical similarity of the digestive tract with that of the human, and to the possibility of resectability.

The criterion for choosing the seventh day after surgery to assess the anastomosis was due to the fact that this time point is within the acute healing response phase. Simultaneously with angiogenesis, fibroblasts begin accumulating in the wound site $2-5$ days after wounding, as the inflammatory phase is ending, and numbers peak at $1-2$ weeks post-wounding. By the end of the first week, fibroblasts are the main cells in the wound. Fibroplasia ends 2-4 weeks after wounding.

Solid foods were restricted in the first 12 hours (liquids were allowed) which was followed by absolute fasting in order to broach only the upper digestive tract, and a povidone and antimicrobial protection solution was used for infection prophylaxis. This prophylaxis, in combination with the precepts of the adopted aseptic surgical technique, contributed significantly to the results obtained in the studied groups.

The surgery was uneventful in most animals; however, in numbers 3 and 8 of group $A$, there was extravasation of urine into the abdominal cavity when applying stitches to secure the urinary bladder. In animal number 9 of group $\mathrm{C}$, there was bleeding from the terminal branch of the gastric artery, which was controlled by clamping. In animal number 5 of group $\mathrm{D}$, difficulty was experienced when introducing the stapler into the abdominal cavity, but there were no difficulties after this point

The presence of macroscopic mucosal necrosis was found in animal number 3 of group B (Table 4), which may have been due to the difficulty in removing the 80 -shear linear stapler device. In the other animals, the presence of macroscopic necrosis was not observed at the suture line. In animal number 8 of group $C$, the presence of necrosis in the microscopic study was noted. In both of these animals (number 3 of group B and number 8 of group C), interstitial hemorrhage was verified.

The operative time, although not separately analyzed, allowed for verification of a faster procedure with mechanical sutures. Mechanical sutures are quicker than manual sutures, which reduces operating time; this is very important for clinically severe patients undergoing surgery. ${ }^{3,7,9}$ Another advantage to their use is in the case of anastomoses in unfavorable anatomical locations for manual sutures, such as in cases of low rectal anastomoses, esophageal anastomoses, or in obese patients.

The presence of anastomotic dehiscence was not observed in any of the animals studied, a result in agreement with literature. ${ }^{17-19}$
The histological evaluation, on the seventh day after surgery, showed healing evolution in all the groups, with no significant statistical difference demonstrated. Postoperative evolution was satisfactory, and there were no deaths and no significant statistical differences observed in the starting time of refeeding, ambulation, or defecation. There was a low incidence of morbidity, although an incisional hernia was observed in animal 3 of group D.

It is important to stress that the presence of a fistula does not represent clinical impairment, but indeed the loss of intestinal contents into the open cavity, which meant that, in three animals (numbers 5 and 7 of group $\mathrm{A}$ and number 6 of group C), despite presenting anastomotic fistulas, no systemic repercussions were encountered, probably due to epiploic adhesions or of neighboring organs. Another relevant point to stress is that the normal experimental model can not be directly transferred to the bariatric model, once histological makeup of bariatric tissues is different, with a high proportion of fat.

Although the results obtained were not statistically significant, the closure of the anastomoses in swine with mechanical sutures presents the advantage of not having to open the intestinal wall within the cavity, thus reducing the risk of contamination of the peritoneal cavity.

\section{Conclusion}

The results obtained from this study demonstrate the similarity, on the seventh day after surgery, be it manually, with simple sutures, or mechanically, with various types of linear staplers, allowing us to conclude that there is a similarity as far as safety, efficacy, and effectiveness are concerned, among the different models of mechanical linear staplers tested for carrying out these anastomoses in swine.

\section{Disclosure}

The authors report no conflicts of interest in this work.

\section{References}

1. Grundmann R, Weber F, Pichlmaier H. [Surgical preparation and technic and perioperative therapy in colorectal interventions: state of the art review]. Med Klin (Munich). 1987;82(15-16):532-537. German.

2. Xu QR, Wang KN, Wang WP, Zhang K, Chen LQ. Linear stapled esophagogastrostomy is more effective than hand-sewn or circular stapler in prevention of anastomotic stricture: a comparative clinical study. J Gastrointest Surg. 2011;15(6):915-921.

3. García-Caballero M, Carbajo M. One anastomosis gastric bypass: a simple, safe and efficient surgical procedure for treating morbid obesity. Nutr Hosp. 2004;19(6):372-375.

4. Oláh A, Dézsi CA. Aladar Petz (1888-1956) and his world-renowned invention: the gastric stapler. Dig Surg. 2002;19(5):393-397; discussion 397-399. 
5. Ravitch MM, Snodgrass E, McEnany T, Rivarola A. Compartmentation of the vena cava with the mechanical stapler. Surg Gynecol Obstet. 1966;122(3):561-566.

6. Ravitch MM, Rivarola A, Van Grov J. Rapid creation of gastric pouches with the use of an automatic stapling instrument. J Surg Res. 1966;6(2): 64-65.

7. Ravitch MM, Lane R, Cornell WP, Rivarola A, McEnany T. Closure of duodenal, gastric and intestinal stumps with wire staples: experimental and clinical studies. Ann Surg. 1966;163(4):573-579.

8. Coney PM, Scott MA, Strachan JR. Small bowel anastomosis with a skin stapler: safe, cost-effective and easily learnt in urological surgery. BJU Int. 2007;100(3):715-717.

9. Böhm B, Milsom JW. Animal models as educational tools in laparoscopic colorectal surgery. Surg Endosc. 1994;8(6):707-713.

10. Nissotakis C, Sakorafas GH, Vugiouklakis D, Kostopoulos P, Peros G. Transanal circular stapler technique: a simple and highly effective method for the management of high-grade stenosis of low colorectal anastomoses. Surg Laparosc Endosc Percutan Tech. 2008;18(4): 375-378.

11. Oprescu C, Beuran M, Nicolau AE, et al. Anastomotic dehiscence (AD) in colorectal cancer surgery: mechanical anastomosis versus manual anastomosis. J Med Life. 2012;5(4):444-451.

12. Izbicki JR, Gawad KA, Quirrenbach S, et al. [Is the stapled suture in visceral surgery still justified? A prospective controlled, randomized study of cost effectiveness of manual and stapler suture]. Chirurg. 1998;69(7):725-734. German.
13. Horisberger K, Beldi G, Candinas D. Loop ileostomy closure: comparison of cost effectiveness between suture and stapler. World $J$ Surg. 2010;34(12):2867-2871.

14. Sánchez-Medina R, Suárez-Moreno R, Aguilar-Soto O, CuéllarGamboa L, Avila-Vargas G, Di Silvio-López M. [Manual mechanical anastomosis colorectal surgery]. Cir Cir. 2003;71(1):39-44. Spanish.

15. Scandroglio I, Di Lernia S, Massazza C, Salatino G, Cocozza E, Pugliese R. [Mechanical entero-enteral anastomosis in surgery of the upper digestive tract]. Minerva Chir. 1997;52(9):1135-1138. Italian.

16. Lange V, Meyer G, Schardey HM, et al. Different techniques of laparoscopic end-to-end small-bowel anastomosis. Surg Endosc. 1995;9:82-87.

17. Reissman P, Teoh TA, Skinner K, Burns JW, Wexner SD. Adhesion formation after laparoscopic anterior resection in a porcine model. Surg Laparosc Endosc. 1996;6:136-139.

18. Cady J, Godfroy J, Sibaud O, Mercadier M. [Anastomotic dehiscence after resection of colon and rectum. Study between manual and mechanical sutures about 149 cases (author's transl)]. Ann Chir. 1980;34(5):350-356. French.

19. Telem DA, Sur M, Tabrizian P, et al. Diagnosis of gastrointestinal anastomotic dehiscence after hospital discharge: impact on patient management and outcome. Surgery. 2010;147(1):127-133.
Open Access Surgery

\section{Publish your work in this journal}

Open Access Surgery is an international, peer-reviewed, open access journal that focuses on all aspects of surgical procedures and interventions. Patient care around the peri-operative period and patient outcomes post surgery are key topics. All grades of surgery from minor cosmetic interventions to major surgical procedures are covered. Novel techniques

Submit your manuscript here: http://www.dovepress.com/open-access-surgery-journal

\section{Dovepress}

and the utilization of new instruments and materials, including implants and prostheses that optimize outcomes constitute major areas of interest. The manuscript management system is completely online and includes a very quick and fair peer-review system. Visit http://www.dovepress.com/ testimonials.php to read real quotes from published authors. 